\title{
Factors influencing basic vaccination coverage in Myanmar: secondary analysis of 2015 Myanmar demographic and health survey data
}

Ikuma Nozaki ${ }^{1,2^{*}}$, Masahiko Hachiya ${ }^{1}$ and Tomomi Kitamura ${ }^{1}$

\begin{abstract}
Background: Immunization is one of the most effective measures for preventing disease when vaccination coverage is sufficient. Although vaccination coverage is known to be influenced by social and cultural barriers, the determinants of childhood immunization in Myanmar remain poorly understood. This study analyzed factors that influenced complete vaccination status (one dose each for Bacillus Calmette-Guérin and measles and three doses each for diphtheria-pertussis and polio) using 2015 data from the Myanmar Demographic Health and Survey.

Methods: Data from 12 to 23-month-old children and their mothers were extracted from the nationally representative survey results. Bivariate and multivariate analyses with survey-weighted logistic regression were performed to examine the relationships between vaccination status and various sociodemographic and medical factors. The independent variables for the analyses included area of residence, economic status, maternal age, marital status, education, literacy, employment status, antenatal care attendance, tetanus vaccination, place of delivery, postnatal evaluations, child's sex, number of children, previous child death, decision maker(s) regarding child's health, frequency of healthcare visits, paternal education, and paternal occupation.
\end{abstract}

Results: A representative sample of 904 cases were extracted for the analysis. The overall complete vaccination rate was $55.4 \%$. In the multivariate analysis with backward step-wise selection, complete vaccination was independently associated with middle or high economic status (adjusted odds ratio [AOR]: 2.64, 95\% confidence interval [Cl]: 1.853.78), older maternal age (AOR: 2.87, 95\% Cl: 1.62-5.10), $\geq 4$ antenatal care visits (AOR: 1.87, 95\% Cl: 1.28-2.73), and maternal tetanus vaccination before delivery (AOR: 3.26, 95\% Cl: 1.82-5.85).

Conclusion: The first Demographic and Health Survey in Myanmar revealed that only approximately one-half of 12-23-year-old children had received complete vaccination, which was lower than the estimated rate from routine administrative coverage. Our results indicate that incomplete immunization status was associated with low economic status, younger maternal age, fewer antenatal care visits, and no maternal tetanus vaccination. These findings may help improve the targeting and strategic implementation of the Expanded Programme on Immunization.

Keywords: Childhood, Immunization, Coverage, Vaccines, Demographic health survey, Myanmar

\footnotetext{
* Correspondence: i-nozaki@it.ncgm.go.jp

${ }^{1}$ Bureau of International Health Cooperation, National Center for Global

Health and Medicine, 1-21-1, Toyama, Shinjuku, Tokyo 162-8655, Japan

${ }^{2}$ Ministry of Health, Naypyidaw, Myanmar
}

(c) The Author(s). 2019 Open Access This article is distributed under the terms of the Creative Commons Attribution 4.0 International License (http://creativecommons.org/licenses/by/4.0/), which permits unrestricted use, distribution, and reproduction in any medium, provided you give appropriate credit to the original author(s) and the source, provide a link to the Creative Commons license, and indicate if changes were made. The Creative Commons Public Domain Dedication waiver (http://creativecommons.org/publicdomain/zero/1.0/) applies to the data made available in this article, unless otherwise stated. 


\section{Background}

Immunization is one of the most successful and cost-effective tools for improving children's health [1]. Furthermore, the public health community agrees that completing a full course of vaccinations against communicable diseases (e.g., measles, polio, and others) helps reduce morbidity and mortality among children. However, childhood vaccination rates vary between and within countries, with low- and middle-income countries remaining vulnerable to vaccine-preventable diseases [2]. In 1974, the World Health Organization launched the Expanded Programme on Immunization (EPI) to help globally control vaccine-preventable diseases [3]. In Myanmar, the EPI was launched in 1978 by introduction of Bacillus Calmette-Guérin (BCG), diphtheria-pertussistetanus (DPT), and tetanus toxoid (TT) vaccines [4]. Vaccines to prevent measles and polio were subsequently added onto the routine vaccination schedule in 1987. The coverage of EPI in Myanmar has gradually expanded from originally 104 of 330 townships at the beginning to 305 townships in 1995, with almost all areas of all townships thought to be covered [4]. As a result, the national immunization coverage rates in 2015 were $86 \%$ for BCG, $75 \%$ for DPT3, $76 \%$ for oral polio vaccine 3 (OPV3), and $86 \%$ for measles-containing-vaccine first-dose. Furthermore, $85 \%$ of the townships have achieved $80 \%$ coverage using pentavalent vaccines and $45 \%$ of the townships have achieved more than $90 \%$ coverage using measles-containing-vaccine first-dose [5].

The first Myanmar Demographic and Health Survey (MDHS) was conducted during 2015-2016, as part of the global Demographic and Health Survey (DHS) Program supported by USAID. It was a nationally representative household survey that used a standardized questionnaire with questions regarding vaccination co verage. The study sample was selected using a stratified two-stage cluster sampling design [6]. The MDHS 2015-16 reported that only $55 \%$ of $12-23$-month-old children had received all basic vaccinations (one dose each for BCG and measles and three doses each for DP and polio), with a noticeable discrepancy between the comparatively high administrative coverage and the comparatively low MDHS-reported coverage. Furthermore, Myanmar has experienced outbreaks of vaccinepreventable diseases in 2015, 2016, and 2017 (e.g., measles, diphtheria, and Japanese encephalitis), even in areas with reportedly high administrative coverage. Moreover, two cases involving a circulating vaccine-derived polio virus were detected in 2015 . Thus, there is a need to better understand the factors that can influence complete vaccination coverage to improve the situation in Myanmar.

Various factors can influence complete vaccination coverage, such as access to the vaccination site $[7,8]$, parental age and education [7-9], household income and wealth $[8,9]$, the child being a girl $[10,11]$, and place of delivery [9, 12]. In addition, Rainey et al. performed a systematic review of non-vaccination and under-vaccination among children in low- and middle-income countries, and proposed that these outcomes were related to the immunization system, family characteristics, parental attitudes and knowledge, and limitations regarding immunization-related communication and information [13]. Therefore, the present study aimed to identify factors that were associated with completion of all basic vaccinations in Myanmar, based on data from the 20152016 MDHS.

\section{Methods}

\section{Study design and data source}

The present study involved a secondary analysis of MDHS data (collected between December 2015 and July 2016). This was the first Myanmar survey as part of the worldwide DHS [6, 14], which aimed to provide policy makers and program managers with up-to-date estimates of basic demographic and health indicators in order to evaluate and develop programs and strategies [6]. A stratified two-stage clustered sampling design was used, with the first stage involving 442 clusters (123 urban and 319 rural clusters) from 30 sampling strata and the second stage involving 30 households from each cluster (i.e., 13,260 households) [6]. All women who were 15-49-years-old, and members of the selected household or visitors who stayed with the selected household the night before the survey, were considered eligible [14]. The selected and eligible women provided maternal and child-related data using the Women's Questionnaire, which was developed for the worldwide DHS program and modified for the Myanmar survey based on its culture and specific health challenges [6]. Vaccination coverage was assessed using both the child's vaccination card and the mother's recollection (as only $45 \%$ of the target children had available vaccination cards).

The DHS Program produces various datasets, including household data, household economic status, women's data, men's data, couples' data, child-related data, and birth-related data. The present study evaluated maternal and children's data, which included records for each child who had been born to the interviewed woman in the 5 years before the survey (i.e., all children were 059 months old). These records contained information related to the mother, pregnancy, postnatal care, immunization, and health.

\section{Statistical analysis}

Data regarding 12-23-month-old children were extracted from the dataset, and all analyses were performed using 
the survey feature of Stata software (version 14.0; StataCorp, College Station, TX). The study outcome was defined as complete vaccination status, which involved receiving one dose each for BCG and measles and three doses each for DPT and polio. We selected 18 variables from the DHS questionnaire that might potentially be associated with immunization status: area of residence, economic status, maternal age, marital status, maternal education, maternal literacy, maternal occupation, antenatal care (ANC) attendance, maternal tetanus vaccination, place of delivery, postnatal evaluation, child's sex, number of children, previous child death, decision maker(s) regarding the child's health, frequency of healthcare visits, paternal education, and paternal occupation. Bivariate analyses were performed to evaluate the relationships between vaccination status and the various factors using survey-weighted logistic regression. Multivariate analyses were subsequently performed using a backward step-wise logistic regression model. Multi-collinearity was tested and an acceptable result was defined as a variance inflation factor of $<10$.

\section{Results}

Children's recode file provided by DHS program contained 4815 data of children under 5-year-old. The present study extracted and evaluated data from 904 mothers and their children who were 12-23 months old. Among these children, only $55.4 \%$ had complete vaccination coverage (one dose each for BCG and measles and three doses each for DP and polio). Table 1 shows that the rates of complete immunization coverage were $67.8 \%$ in urban settings and $50.9 \%$ in rural settings. According to maternal education, the complete coverage rates were $51.2 \%$ for no or primary education and $61.4 \%$ for secondary or higher education. According to economic status, the complete coverage rates were $41.4 \%$ for low economic status and $69.2 \%$ for middle or high economic status. According to maternal age, the complete coverage rates were $42.1 \%$ for $15-24$ years old, $57.2 \%$ for $25-34$ years old, and $63.9 \%$ for $\geq 35$ years old. The complete coverage rates were $62.0 \%$ for home delivery and $49.4 \%$ for delivery in a healthcare setting. The complete coverage rates were $58.2 \%$ for male children and $51.7 \%$ for female children.

In the bivariate analysis, complete vaccination coverage was associated with urban residence (odds ratio [OR]: 2.03, 95\% confidence interval [CI]: 1.35-3.04), middle or high economic status (OR: 3.18, 95\% CI: 2.26-4.47), older maternal age (OR: 2.50 , 95\% CI: $1.52-$ 4.11), greater maternal education (OR: $1.52,95 \% \mathrm{CI}$ : 1.10-2.09), maternal literacy (OR: 1.68, 95\% CI: 1.142.49), $\geq 4$ ANC visits (OR: 3.01, 95\% CI: 2.09-4.34), maternal tetanus vaccination before delivery (OR: $3.68,95 \%$ CI: 1.99-6.81), home birth (OR: 1.67, 95\% CI: 1.19-
2.33), no previous child death in the household (OR: 1.77, 95\% CI: 1.07-2.92), visiting a healthcare facility during the last 12 months (OR: 1.59, 95\% CI: 1.13-2.24), greater paternal education (OR: 2.10, 95\% CI: 1.492.97), and skilled paternal occupation (OR: 1.60, 95\% CI: 1.10-2.32) (Table 1).

The multivariate analysis with backward step-wise selection revealed that complete vaccination coverage remained independently associated with middle or high economic status (adjusted OR [AOR]: 2.64, 95\% CI: 1.85-3.78), older maternal age (AOR: $2.87,95 \% \mathrm{CI}$ : 1.62-5.10), $\geq 4$ ANC visits (AOR: 1.87, 95\% CI: 1.28 2.73 ), and maternal tetanus vaccination before delivery (AOR: 3.26, 95\% CI: 1.82-5.85). The final model also included no previous child death in the household, although the results were not significant (AOR: 1.60, 95\% CI: 0.92-2.78) (Table 2).

\section{Discussion}

Although the benefits of vaccination are widely recognized, a global estimate indicated that 19,500,000 infants in 2016 were not covered by routine immunization services, such as the DTP3 vaccine [15]. Moreover, despite Myanmar's remarkable progress in early vaccination efforts, the rate of complete coverage has not been improving during recent years [4]. For example, the MDHS data revealed that only $55 \%$ of $12-23$-month-old children had complete vaccination coverage, which is lower than the WHO-UNICEF estimates of routine administrative coverage from 2014, such as $86 \%$ coverage for BCG, $75 \%$ coverage for DTP3, 76\% coverage for OPV3, and $86 \%$ coverage for measles-containing-vaccine first-dose [16]. Although the population coverage required to achieve herd immunity varies according to disease, the ideal target is $100 \%$ coverage because va ccination coverage is not a perfect measure of population-level immunity. One author has described this concept as "everyone who can get vaccinated, should get vaccinated - not only to protect themselves, but to protect those who can't, through herd immunity" [17]. Therefore, we evaluated factors that were related to complete vaccination coverage in Myanmar, and found that complete coverage was independently associated with higher economic status, older maternal age, $\geq 4$ ANC visits, maternal tetanus vaccination before delivery, and no previous child death in the household.

Because socioeconomic status is known to be associated with vaccination coverage [18-23], we used the DHS wealth index to assess household socioeconomic status. This index provides a composite measure of a household's cumulative living standard, which is categorized into 5 wealth quintiles and is used to quantify whether household economic status affects health outcomes. The wealth index is calculated based on easily 
Table 1 Full vaccination coverage and related factors among 12-23-month-old children in Myanmar

\begin{tabular}{|c|c|c|c|c|}
\hline & Weighted number of respondents & Full vaccination \% $(95 \% \mathrm{Cl})$ & Crude OR (95\% Cl) & $p$-value \\
\hline \multicolumn{5}{|l|}{ Area of residence } \\
\hline Urban & 207 & $67.8(60.4-75.2)$ & REF & \\
\hline Rural & 697 & $50.9(45.2-56.6)$ & $0.493(0.329-0.740)$ & 0.001 \\
\hline \multicolumn{5}{|l|}{ Economic status } \\
\hline Low & 459 & $41.4(34.9-47.8)$ & REF & \\
\hline Middle or high & 440 & $69.2(63.9-74.5)$ & $3.178(2.259-4.470)$ & $<0.001$ \\
\hline \multicolumn{5}{|l|}{ Maternal age } \\
\hline $15-24$ years & 207 & $42.1(34.0-50.2)$ & REF & \\
\hline $25-34$ years & 474 & $57.2(51.4-63.0)$ & $1.828(1.233-2.711)$ & 0.003 \\
\hline$\geq 35$ years & 214 & $63.9(55.3-72.6)$ & $2.503(1.524-4.111)$ & $<0.001$ \\
\hline \multicolumn{5}{|l|}{ Marital status } \\
\hline Separated (any reason) & 29 & $41.2(15.4-66.9)$ & REF & \\
\hline Married & 868 & $55.8(51.0-60.7)$ & $1.608(0.732-3.535)$ & 0.236 \\
\hline \multicolumn{5}{|l|}{ Maternal education } \\
\hline None/primary school & 528 & $51.2(45.0-57.5)$ & REF & \\
\hline Secondary or higher & 374 & $61.4(56.0-66.9)$ & $1.515(1.097-2.091)$ & 0.012 \\
\hline \multicolumn{5}{|l|}{ Maternal literacy } \\
\hline Cannot read sentences & 245 & $45.1(35.8-54.4)$ & REF & \\
\hline Can read sentences & 654 & $58.9(54.4-63.3)$ & $1.681(1.137-2.485)$ & 0.009 \\
\hline \multicolumn{5}{|l|}{ Maternal employment } \\
\hline Unemployed & 361 & $55.6(48.2-62.9)$ & REF & \\
\hline Unskilled employee & 328 & $49.9(42.9-57.0)$ & $0.807(0.543-1.198)$ & 0.286 \\
\hline Skilled employee & 207 & $62.2(53.5-70.9)$ & $1.316(0.841-2.058)$ & 0.228 \\
\hline \multicolumn{5}{|l|}{ ANC attendance } \\
\hline $0-3$ times & 341 & $37.7(30.2-45.1)$ & REF & \\
\hline$\geq 4$ times & 554 & $65.4(60.6-70.3)$ & $3.012(2.093-4.335)$ & $<0.001$ \\
\hline \multicolumn{5}{|l|}{ Tetanus vaccination } \\
\hline No & 89 & $25.9(14.8-37.1)$ & REF & \\
\hline Once or more & 803 & $58.7(54.3-63.1)$ & 3.677 (1.985-6.809) & $<0.001$ \\
\hline \multicolumn{5}{|l|}{ Place of birthing } \\
\hline Healthcare setting & 523 & $49.4(42.9-55.9)$ & REF & \\
\hline Home & 377 & $62.0(56.3-67.6)$ & $1.667(1.185-2.326)$ & 0.003 \\
\hline \multicolumn{5}{|l|}{ Postnatal evaluation } \\
\hline Not within 2 months & 453 & $53.0(47.3-58.7)$ & REF & \\
\hline Yes & 412 & $57.8(51.6-63.9)$ & $1.202(0.877-1.649)$ & 0.252 \\
\hline \multicolumn{5}{|l|}{ Child's sex } \\
\hline Male & 499 & $58.2(52.3-64.2)$ & REF & \\
\hline Female & 404 & $51.7(45.6-57.8)$ & $0.764(0.550-1.061)$ & 0.108 \\
\hline \multicolumn{5}{|l|}{ Number of children } \\
\hline 1 & 501 & $57.5(51.5-63.6)$ & REF & \\
\hline$\geq 2$ & 401 & $52.0(46.0-58.0)$ & $0.800(0.576-1.111)$ & 0.182 \\
\hline \multicolumn{5}{|l|}{ Prior child death } \\
\hline Never & 775 & $57.0(52.2-61.8)$ & REF & \\
\hline Ever & 123 & $43.4(29.6-57.2)$ & $0.566(0.342-0.935$ & 0.026 \\
\hline
\end{tabular}


Table 1 Full vaccination coverage and related factors among 12-23-month-old children in Myanmar (Continued)

\begin{tabular}{|c|c|c|c|c|}
\hline \multicolumn{5}{|l|}{ Child health decisions } \\
\hline Mother alone & 502 & $57.9(52.2-63.5)$ & REF & \\
\hline Mother + other(s) & 400 & $51.9(45.8-58.1)$ & $0.789(0.580-1.074)$ & 0.131 \\
\hline \multicolumn{5}{|l|}{ Healthcare visits } \\
\hline Not in last 12 months & 421 & $49.0(42.4-55.7)$ & REF & \\
\hline Visit in last 12 months & 482 & $60.5(54.8-66.2)$ & 1.589 (1.127-2.241 & 0.008 \\
\hline \multicolumn{5}{|l|}{ Paternal education } \\
\hline None/primary school & 493 & $47.2(41.0-53.5)$ & REF & \\
\hline Secondary or higher & 407 & $65.3(59.5-71.2)$ & $2.101(1.489-2.965)$ & $<0.001$ \\
\hline \multicolumn{5}{|l|}{ Paternal occupation } \\
\hline Unskilled employee & 586 & $50.8(45.2-56.5)$ & REF & \\
\hline Skilled employee & 312 & $62.6(55.2-70.0)$ & $1.597(1.098-2.322)$ & 0.014 \\
\hline
\end{tabular}

Cl: confidence interval, OR: odds ratio, REF: reference category, $A N C$ antenatal care

collected data regarding select assets, such as televisions, bicycles, and materials used for housing construction, and types of water access and sanitation facilities, because reliable data regarding income and expenditures (i.e., the traditional indicators of household economic status) are not available in many countries [24]. The present study revealed a strong association between higher economic status and full vaccination coverage. However, this relationship may also be confounded by other well-known predictors of complete vaccination coverage, such as maternal education and literacy or the area of residence (urban or rural) [25, 26]. The present study revealed strong associations between the wealth

Table 2 Multivariable logistic regression analysis of full immunization coverage among 12-23-month-old children

\begin{tabular}{lll}
\hline & Adjusted OR $(95 \% \mathrm{Cl})$ & $p$-value \\
\hline Economic status & & \\
Low & REF & $<0.001$ \\
Middle or high & $2.642(1.848-3.778)$ & \\
Maternal age & & \\
15-24 years & REF & 0.004 \\
25-34 years & $1.895(1.227-2.926)$ & $<0.001$ \\
$\geq 35$ years & $2.870(1.620-5.102)$ & \\
ANC attendance & & 0.001 \\
0-3 times & REF & \\
$\geq 4$ times & $1.871(1.283-2.727)$ & \\
Tetanus vaccination & & \\
No & REF & 0.001 \\
Once or more & $3.260(1.816-5.851)$ & \\
Prior child death & & \\
Ever & REF & \\
Never & $1.600(0.921-2.778)$ & \\
\hline
\end{tabular}

Cl confidence interval, $O R$ odds ratio, REF: reference category, ANC antenatal care index and maternal education $(p<0.001)$, maternal literacy $(p<0.001)$, and area of residence $(p<0.001)$. Although these factors were significant in the bivariate analyses, they were no significant in the multivariate analyses. In contrast, older maternal age remained an independent predictor in the multivariate analysis. Interestingly, previous studies have indicated that maternal age was both negatively and positively correlated with complete vaccination coverage [22, 27, 28].

Child sex and the number of children in the household are also well-known predictors of vaccination coverage in some social contexts $[10,11,29]$. However, these factors were not significant in Myanmar, although we did observe slightly higher complete vaccination coverage rates among male children ( $58 \%$ vs. $52 \%$ ) and single children versus households with $\geq 2$ children ( $58 \%$ vs. $52 \%$ ). Maternal empowerment may also influence vaccination coverage in some countries [30-32]. Thus, we evaluated the complete vaccination coverage rates for households where the mother made all health-related decisions and households where the mother had to consult other people, although we failed to detect a significant difference between these two groups.

Several studies have indicated that complete immunization coverage is associated with various maternal healthcare utilization indices, such as ANC attendance, pre-birth TT immunization, skilled birth attendance, and delivery in a healthcare facility [33-36]. Danchin et al. have reported that vaccination decision making begins during pregnancy [37], and we also found that complete vaccination coverage was associated with maternal ANC attendance and pre-birth TT immunization. However, we found that complete vaccination coverage was less common for births at a healthcare facility, relative to home births, although this difference was not significant in the multivariate analysis. This is likely related to the relationship between ANC attendance and home birthing $(p<$ 
0.001), although the cause of this relationship remains unclear and further research is needed to better understand why Myanmar women would select a home birth if they frequently attended ANC visits.

During the planning phase of this study, we assumed that households who had previously experienced a child's death might be more likely to vaccinate subsequent children, relative to households who had not experienced a child's death. However, we were surprised to find that households with a previous child's death had a lower complete vaccination rate. Nevertheless, households with a previous child's death had a relatively low economic status $(p<0.001)$, which also strongly predicts incomplete immunization coverage. Therefore, a previous child's death may be related to the household's low economic status, less attention paid to the child's health, and incomplete vaccination. Vaccination to child's death, vaccination avoidance due to misunderstandings relating vaccination to previous child's death could also be possible explanation for this. Further studies are needed to understand the healthcare perspectives of caretakers who have lost a child, as healthcare workers and health officials may need to use a different approach for these individuals. As an alternate indirect index for healthcare access, we evaluated whether the mother had visited a healthcare facility during the last 12 months. Similar to a previous report [38], we found a significant association between a recent healthcare visit and complete vaccination, although this relationship was not significant in the multivariate analysis. Therefore, further studies are needed to better understand the barriers to healthcare access in Myanmar.

The present study has several limitations. For example, only extracting data for 12-23-month-old children may have introduced bias (the sample unit for the 2015-2016 MDHS was households). Since vaccination coverage was assessed using both the child's vaccination card and the mother's recollection according to WHO recommendations, there were potential risk of recall bias and subject bias that mothers of children who don't have the vaccination card tend to report a vaccination for their children due to shame and stigma [38]. Furthermore, the DHS is not designed to assess the EPI program status, as it does not consider factors that can influence immunization systems, such as access and distance from the vaccination services, missed vaccination opportunities, and limited availability and knowledge of health workers [13]. Although these factors are known to affect vaccine coverage, the present study was only able to evaluate them using indirect measures (e.g., healthcare facility use within the past year and area of residence). The present study also failed to evaluate regional variations in complete vaccination coverage, as the small number of children in each state/region would have produced a low statistical power. Moreover, other countries have had discrepancies between the vaccination coverage rate and population-level immunity for vaccine-preventable diseases, which may be related to insufficient cold chain control and the vaccine's heat sensitivity [39]. Thus, to evaluate the risks of related outbreaks, direct immunity assessment is needed (e.g., seroepidemiological analysis). Therefore, combining the DHS with serological assessments would greatly improve our ability to understand regional differences and discrepancies between the vaccination coverage rate and population-level immunity, as the DHS data are representative of the region's general population. Despite these limitations, secondary analysis of DHS data is thought to substantially contribute to public health knowledge in developing countries [40, 41], and we believe that our findings can help inform decisions regarding related policies and programs.

\section{Conclusion}

The first MDHS revealed a complete vaccination coverage rate of only $55 \%$ among $12-23$-month-old children, which is lower than the estimated rate from routine administrative coverage. The present study also revealed that incomplete vaccination coverage was independently associated with low economic status, younger maternal age, fewer ANC visits, and no pre-birth maternal tetanus vaccination. These findings may help the EPI program more specifically target and better address these demographic groups. However, further studies are needed to understand the relationships between maternal healthcare utilization (e.g., birthing location), immunization system-related factors (e.g., access and distance from the vaccination services), and population-level immunity.

\section{Abbreviations \\ ANC: antenatal care; BCG: Bacillus Calmette-Guérin; Cl: confidence interval; DHS: Demographic and Health Survey; DPT: diphtheria-pertussis-tetanus; EPI: The Expanded Program on Immunization; OPV: oral polio vaccine; OR: odds ratio; $T$ T: tetanus toxoid}

\section{Acknowledgments}

The authors thank the DHS program for providing the data. We also thank Dr. Tetsuya Mizoue (Department of Epidemiology and Prevention, Center for Clinical Sciences, National Center for Global Health and Medicine) for his support with the statistical analysis.

\section{Ethics approval and consent to participate}

The study involved a secondary analysis of anonymized data from the 2015 Myanmar Demographic and Health Survey (MDHS). The protocol for the 2015-2016 MDHS was reviewed and approved by the Ethics Review Committee on Medical Research including Human Subjects (Department of Medical Research, Ministry of Health and Sports). Data for the current study were obtained from the MEASURE DHS website using the standard data acquisition procedure.

\section{Funding}

This study was supported by a grant from the National Center for Global Health and Medicine (28S-1). This funding body had no role in the design of the study and collection, analysis, and interpretation of data and in writing the manuscript. 


\section{Availability of data and materials}

The dataset used in this article is available from the MEASURE DHS website: https://dhsprogram.com/data/dataset/Myanmar_Standard-

DHS_2016.cfm?flag=1.

\section{Authors' contributions}

IN conceived of and designed the study with support from MH and TK. IN applied to the DHS program to obtain the dataset. TK led the statistical analysis. IN drafted the manuscript with the help of MH and TK. All authors read and approved the final manuscript.

\section{Consent for publication}

Not applicable.

\section{Competing interests}

The authors declare that they have no competing interests.

\section{Publisher's Note}

Springer Nature remains neutral with regard to jurisdictional claims in published maps and institutional affiliations.

\section{Received: 2 September 2018 Accepted: 14 February 2019}

\section{Published online: 28 February 2019}

\section{References}

1. Bloom DE, Canning D, Weston M. The value of vaccination. World Econ. 2005;6:15-39.

2. Clark A, Sanderson C. Timing of children's vaccinations in 45 low-income and middle-income countries: an analysis of survey data. Lancet. 2009;373: $1543-9$.

3. Keja K, Chan C, Hayden G, Henderson RH. Expanded programme on immunization. World Health Stat Q. 1988:41:59-63.

4. Myanmar Ministry of Health. Expanded Programme on Immunization Myanmar Multi Year Plan 2012-2016. http://www.searo.who.int/myanmar/ documents/EPImultiyearplan2012 16.pdf?ua=1. Accessed 28 Aug 2018.

5. World Health Organization. Myanmar EPI Fact Sheet 2016. http://www.searo. who.int/entity/immunization/data/myanmar.pdf?ua=1. Accessed 28 Aug 2018.

6. Myanmar Ministry of Health and Sports and ICF. Myanmar Demographic and Health Survey 2015-16. Nay Pyi Taw, Myanmar and Rockville, Maryland USA: Ministry of Health and Sports and ICF; 2017.

7. Jani JV, De Schacht C, Jani IV, Bjune G. Risk factors for incomplete vaccination and missed opportunity for immunization in rural Mozambique. BMC Public Health. 2008;8:161.

8. Mitchell S, Andersson N, Ansari NM, Omer K, Soberanis JL, Cockcroft A. Equity and vaccine uptake: a cross-sectional study of measles vaccination in Lasbela District. Pakistan BMC Int Health Hum Rights. 2009;9(Suppl 1):S7.

9. Mutua MK, Kimani-Murage E, Ettarh RR. Childhood vaccination in informal urban settlements in Nairobi, Kenya: who gets vaccinated? BMC Public Health. 2011;11:6.

10. Pande RP, Yazbeck AS. What's in a country average? Wealth, gender, and regional inequalities in immunization in India. Soc Sci Med. 2003;57:207588.

11. Pande RP. Selective gender differences in childhood nutrition and immunization in rural India: the role of siblings. Demography. 2003:40:395418.

12. Canavan ME, Sipsma HL, Kassie GM, Bradley EH. Correlates of complete childhood vaccination in east African countries. PLoS One. 2014;9:e95709.

13. Rainey JJ, Watkins M, Ryman TK, Sandhu P, Bo A, Banerjee K. Reasons related to non-vaccination and under-vaccination of children in low and middle income countries: findings from a systematic review of the published literature, 1999-2009. Vaccine. 2011;29:8215-21.

14. Surveys TDPDaH. Myanmar: Standard DHS, 2015-16. http://dhsprogram. com/what-we-do/survey/survey-display-454.cfm. Accessed 28 Aug 2018.

15. World Health Organization. Fact sheet on immunization coverage, Updated July 2017 2017. https://www.who.int/en/news-room/fact-sheets/detail/ immunization-coverage. Accessed 28 Aug 2018.

16. Myanmar Ministry of Health and Sports. Expanded Program on Immunization Multi Year Plan 2017-2021. http://www. nationalplanningcycles.org/sites/default/files/planning_cycle_repository/ myanmar/myanmar_cmyp_2017-2021.pdf. Accessed 28 Aug 2018.
17. Salathé M. Herd immunity and measles: why we should aim for 100\% vaccination coverage in 2017. http://theconversation.com/herd-immunityand-measles-why-we-should-aim-for-100-vaccination-coverage-36868. Accessed 28 Aug 2018.

18. Tauil Mde C, Sato AP, Waldman EA. Factors associated with incomplete or delayed vaccination across countries: a systematic review. Vaccine. 2016;34: $2635-43$.

19. Clouston S, Kidman R, Palermo T. Social inequalities in vaccination uptake among children aged 0-59 months living in Madagascar: an analysis of demographic and health survey data from 2008 to 2009. Vaccine. 2014;32: 3533-9.

20. Debnath $\mathrm{A}$, Bhattacharjee $\mathrm{N}$. Wealth-based inequality in child immunization in India: a decomposition approach. J Biosoc Sci. 2018;50:312-25.

21. Anello P, Cestari L, Baldovin T, Simonato L, Frasca G, Caranci N, et al. Socioeconomic factors influencing childhood vaccination in two northern Italian regions. Vaccine. 2017;35:4673-80.

22. Oleribe O, Kumar V, Awosika-Olumo A, Taylor-Robinson SD. Individual and socioeconomic factors associated with childhood immunization coverage in Nigeria. Pan Afr Med J. 2017;26:220.

23. Lauridsen J, Pradhan J. Socio-economic inequality of immunization coverage in India. Health Econ Rev. 2011;1:11.

24. Rutstein SO, Johnson K. The DHS wealth index. Calverton: ORC Macro; 2004.

25. Xeuatvongsa A, Hachiya M, Miyano S, Mizoue T, Kitamura T. Determination of factors affecting the vaccination status of children aged 12-35 months in Lao People's Democratic Republic. Heliyon. 2017;(3):e00265.

26. Bbaale E. Factors influencing childhood immunization in Uganda. J Health Popul Nutr. 2013:31:118-29.

27. Emmanuel OW, Samuel AA, Helen KL. Determinants of childhood vaccination completion at a peri-urban hospital in Kenya, December 2013 -January 2014: a case control study. Pan Afr Med J. 2015;20:277.

28. Tsuchiya Y, Shida N, Izumi S, Ogasawara M, Kakinuma W, Tsujiuchi T, et al. Factors associated with mothers not vaccinating their children against mumps in Japan. Public Health. 2016;137:95-105.

29. Merten S, Martin Hilber A, Biaggi C, Secula F, Bosch-Capblanch X, Namgyal $P$, et al. Gender determinants of vaccination status in children: evidence from a meta-ethnographic systematic review. PLoS One. 2015;10:e0135222.

30. Thorpe S, VanderEnde K, Peters C, Bardin L, Yount KM. The influence of Women's empowerment on child immunization coverage in low, lowermiddle, and upper-middle income countries: a systematic review of the literature. Matern Child Health J. 2016;20:172-86.

31. Khan MT, Zaheer S, Shafique K. Maternal education, empowerment, economic status and child polio vaccination uptake in Pakistan: a population based cross sectional study. BMJ Open. 2017;7:e013853.

32. Pratley P. Associations between quantitative measures of women's empowerment and access to care and health status for mothers and their children: a systematic review of evidence from the developing world. Soc Sci Med. 2016;169:119-31.

33. Adedire EB, Ajayi I, Fawole Ol, Ajumobi O, Kasasa S, Wasswa P, et al. Immunisation coverage and its determinants among children aged 12-23 months in Atakumosa-west district, Osun state Nigeria: a cross-sectional study. BMC Public Health. 2016;16:905.

34. Restrepo-Mendez MC, Barros AJ, Wong KL, Johnson HL, Pariyo G, Wehrmeister $\mathrm{FC}$, et al. Missed opportunities in full immunization coverage: findings from low- and lower-middle-income countries. Glob Health Action. 2016;9:30963.

35. Rossi R. Do maternal living arrangements influence the vaccination status of children age 12-23 months? A data analysis of demographic health surveys 2010-11 from Zimbabwe. PLoS One. 2015;10:e0132357.

36. Etana $\mathrm{B}$, Deressa $W$. Factors associated with complete immunization coverage in children aged 12-23 months in ambo Woreda, Central Ethiopia. BMC Public Health. 2012;12:566.

37. Danchin MH, Costa-Pinto J, Atwell K, Willaby H, Wiley K, Hoq M, et al. Vaccine decision-making begins in pregnancy: correlation between vaccine concerns, intentions and maternal vaccination with subsequent childhood vaccine uptake. Vaccine. 2017. https://doi.org/10.1016/j.vaccine.2017.08.003.

38. Mbengue MAS, Sarr M, Faye A, Badiane O, Camara FBN, Mboup S, et al. Determinants of complete immunization among senegalese children aged 12-23 months: evidence from the demographic and health survey. BMC Public Health. 2017;17:630.

39. Hachiya M, Miyano S, Mori Y, Vynnycky E, Keungsaneth P, Vongphrachanh P, et al. Evaluation of nationwide supplementary immunization in Lao People's 
Democratic Republic: population-based seroprevalence survey of antimeasles and anti-rubella lgG in children and adults, mathematical modelling and a stability testing of the vaccine. PLoS One. 2018;13: e0194931.

40. Boerma JT, Sommerfelt AE. Demographic and health surveys (DHS): contributions and limitations. World Health Stat Q. 1993:46:222-6.

41. Short Fabic M, Choi Y, Bird S. A systematic review of demographic and health surveys: data availability and utilization for research. Bull World Health Organ. 2012;90:604-12.

Ready to submit your research? Choose BMC and benefit from:

- fast, convenient online submission

- thorough peer review by experienced researchers in your field

- rapid publication on acceptance

- support for research data, including large and complex data types

- gold Open Access which fosters wider collaboration and increased citations

- maximum visibility for your research: over $100 \mathrm{M}$ website views per year

At $\mathrm{BMC}$, research is always in progress.

Learn more biomedcentral.com/submissions 